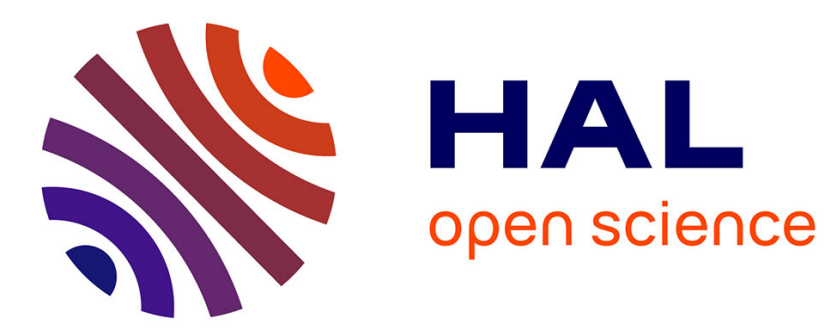

\title{
Rough surfaces of titanium and titanium alloys for implants and prostheses
}

Egle Conforto, Bjorn-Owe Aronsson, A. Salito, Catherine Crestou, Daniel Caillard

\section{- To cite this version:}

Egle Conforto, Bjorn-Owe Aronsson, A. Salito, Catherine Crestou, Daniel Caillard. Rough surfaces of titanium and titanium alloys for implants and prostheses. Materials Science and Engineering: C, 2004, 24, pp.611- 618. 10.1016/j.msec.2004.08.004 . hal-00505436

\section{HAL Id: hal-00505436 https://hal.science/hal-00505436}

Submitted on 23 Jul 2010

HAL is a multi-disciplinary open access archive for the deposit and dissemination of scientific research documents, whether they are published or not. The documents may come from teaching and research institutions in France or abroad, or from public or private research centers.
L'archive ouverte pluridisciplinaire HAL, est destinée au dépôt et à la diffusion de documents scientifiques de niveau recherche, publiés ou non, émanant des établissements d'enseignement et de recherche français ou étrangers, des laboratoires publics ou privés. 


\title{
ROUGH SURFACES OF TITANIUM AND TITANIUM ALLOYS FOR IMPLANTS AND PROSTHESES
}

\author{
${ }^{1}$ E. Conforto, ${ }^{2}$ B.-O.Aronsson, ${ }^{3}$ A. Salito, ${ }^{4}$ C. Crestou and ${ }^{4}$ D. Caillard \\ ${ }^{1}$ Swiss Federal Institute of Technology (EPFL), CH-1015, Lausanne, Switzerland; ${ }^{2}$ GAP Biomedical, \\ University of Geneva, CH-1211 Geneva 4, Switzerland; ${ }^{3}$ Sulzer-Metco AG, CH-5610 Wohlen, Switzerland; \\ ${ }^{4}$ CEMES/CNRS, 29 rue Jeanne Marvig, F-31055 Toulouse Cedex 4, France.
}

\begin{abstract}
Titanium and titanium alloys for dental implants and hip prostheses were surface-treated and/or covered by metallic or ceramic rough layers after being submitted to sand blasting. The goal of these treatments is to improve the surface roughness and, consequently, the osteointegration, the fixation and the stability of the implant. The microstructure of titanium and titanium alloys submitted to these treatments has been studied and correlated to their mechanical behavior. Astreated/covered and mechanically tested surfaces were characterized by scanning electron microscopy. Structural analyses performed by transmission electron microscopy, mainly in crosssection, reveal the degree of adherence and cohesion between the surface layer and the substrate (implant). We observed that, although the same convenient surface roughness was obtained with the two types of process, many characteristics as structural properties and mechanical behavior are very different.
\end{abstract}

Keywords: SLA-treated titanium - Titanium-covered Ti6Al4V alloys - transmission and scanning electron microscopy - titanium hydride layer - interfacial titanium oxide layer 


\section{Introduction}

To be used as an implant, biomaterials must exhibit high biocompatibility and long life in the human body (more than 20 years) without any corrosion, fracture or delaminating. Good mechanical properties are required, mostly high resistance to fatigue and wear. Good mechanical interlocking is also necessary because the fixation of the implant is not guaranteed by the chemical interactions with the biological tissue, which are too weak. For these reasons, the interest for the influence of surface roughness on biological interactions has recently increased, being the subject of many studies.

Surface treatments and coatings deposited by different techniques have been developed in order to provide a micrometrical roughness of the size of bone cells, to guarantee the best possible osteointegration, anchorage and stability. In this sense, the best candidates to be used as biomaterials are titanium and its alloys, surface-treated or covered by metallic or ceramic rough layers. Prior to chemical etching or coverage deposition, the surfaces of titanium and titanium alloys are bombarded ("sand-blasted") with a jet of $\mathrm{Al}_{2} \mathrm{O}_{3}$ particles of $\sim 250 \mu \mathrm{m}$ in size.

One way to obtain the final roughness is to treat the surface by SLA ("Sand-blasting and acid etching", developed by Institut Straumann AG). It consists of an acid ( $\mathrm{HCl} / \mathrm{H}_{2} \mathrm{SO}_{4}$ hot solution) etching performed on $\mathrm{Ti}$ dental implants after the sand-blasting, and results in a two-level roughness: sub-micron porosity superimposed on a $20-50 \mu \mathrm{m}$ roughness. This roughness was characterized by SEM by Wieland [1] and Massaro et al. [2]. Previous works [3] on the chemical characterization of commercially pure $\mathrm{Ti}$ surfaces treated by SLA revealed the presence of hydrogen in the sub-surface layer after acid etching. The authors formulated the hypothesis of the formation of another phase, a titanium hydride. If confirmed, this hydride layer could be responsible for the mechanical properties of the Ti surface after SLA treatment, and also contribute to those of 
the surface/bulk interface.

Another way to obtain the desired final roughness is to coat Ti6Al4V alloys for hip prostheses with a thermal-sprayed titanium layer. Thermal spray is a highly cost-effective and straightforward method [4]. The material to be deposited (Ti) is heated and propelled as droplets, in a molten or near-molten state to the target substrate (prosthesis) after sand blasting. It results in a porous $\mathrm{Ti}$ coating with a typical open porosity of $15-40 \%$, allowing bone cells to growth into the voids. The coating roughness is of $\sim 100 \mu \mathrm{m}$ in width. In previous statements, it was reported that debris were delivered in the body. In addition, the coating sometimes delaminates and some embrittlement of the substrate has been observed.

In the present work, we analyze the surface layer of Ti implants after SLA treatment and that of Ti6A14V hip prostheses after $\mathrm{Ti}$ thermal spray deposition, in terms of chemistry and crystallographic structure. We also examine the crystallographic relationships between the different surface layers and their corresponding substrates. The mechanical behavior of surface layers and substrates are discussed, with reference to preliminary mechanical tests. The characteristics of the surface layer as well as the layer/substrate interface obtained by the two different techniques are then compared.

\section{Experimental}

Commercially pure (c.p.) polycrystalline titanium disks submitted to the SLA surface treatment [4] after polishing were provided by Institut Straumann AG (Waldenburg, CH). Ti6Al4V hip prostheses, tested by ISO/DIS 7206-4 standard and covered by a Ti layer with two different grain sizes, were provided by Sulzer-Metco. In the latter specimens, the finer coating was $70-100 \mu \mathrm{m}$ rough and the coarser one, 200 - $250 \mu \mathrm{m}$. Depositions were performed under argon atmosphere in 
the 20 - 1000 mbar range, the oxygen concentration being kept below $300 \mathrm{ppm}$. The temperature of the substrate (prosthesis) varied between 50 and $300{ }^{\circ} \mathrm{C}$ during the spray projection.

The surfaces of as-received and mechanically tested samples were observed by scanning electron microscopy (SEM) using a field-emission gun. The instrument was a Philips XL-30 FEG microscope, operated at $10 \mathrm{kV}$. Micro-indentation tests were performed on as-received samples with a SOPELEM micro-indenter, equipped with a Vickers pyramid. Loads were applied in the 20 $1200 \mathrm{~g}$ range. Flexion tests were also performed in order to strain the surface layer in tension.

Analyses were performed by transmission electron microscopy (TEM) on cross-sectional specimens. They were prepared from the same specimens observed by SEM, by the classical method: two parts cut perpendicularly to the surface were sandwiched together with epoxy glue, surface against surface. Slices were then cut, mechanically polished and thinned to the perforation by ion milling. Observations were carried out on a Philips EM-430, operated at $300 \mathrm{KV}$, and a JEOL 2010, operated at $200 \mathrm{kV}$. Local chemical analyses were performed by Energy Dispersive Spectroscopy (EDS), simultaneously to TEM observations.

\section{Results and Discussion}

\subsection{SLA-treated c. p. Ti}

\subsubsection{SEM observations}

The surface observed by SEM in Fig. 1 exhibits the same two-level roughness reported in previous works ([1], [2]). According to the authors, the largest roughness (20-50 $\mu \mathrm{m}$ in diameter) is due to the bombardment with $\mathrm{Al}_{2} \mathrm{O}_{3}$ particles while the finer microstructure, with cavities of typically 0.5 to few $\mu \mathrm{m}$ in diameter, is due to the acid etching. One alumina particle from sand blasting remained 
encrusted even after acid etching (Fig. 1a), causing very few cracks (see arrow) around it. Figs. 1b shows an indentation print obtained with high load (1200 g), allowing to evaluate the mechanical behavior of the surface layer under compression. Several features typical of a heavy plastic deformation are present around them: regular crushed zones reproducing the pyramid shape, and pads all around it. Few cracks can also be seen in both figures, which have a ductile aspect.

A bending test has been performed, for which the surface layer has been strained by $2 \%$ in tension, as it can be seen in the lateral view of Fig. 1c. The surface has been subsequently observed by SEM. The images reveal a few cracks perpendicularly to the straining axis, as in Fig. 1d. These cracks are $10 \mu \mathrm{m}$ long in average, and homogeneously distributed. A precise measurement of their widths (from $30 \mathrm{~nm}$ to $60 \mathrm{~nm}$ ) and density (one crack every $20 \mu \mathrm{m}$ along the straining axis) shows that they account for less than $20 \%$ of the total strain. Accordingly, the remaining $80 \%$ must be accommodated either by micro-cracks narrower than $5 \mathrm{~nm}$, or by plastic deformation. No delaminating is observed in the vicinity of cracks or indentation prints, which indicates a good adherence between the substrate and the surface layer.

\subsubsection{Cross-sectional TEM on Ti-SLA samples}

Fig. 2a is a low-magnification cross-sectional TEM image showing, on both sides, the profile of the specimen. The latter is constituted of tips and valleys as previously observed by SEM. The interface with the Ti substrate is found at approximately $2-3 \mu \mathrm{m}$ below the bottom of each valley. The total thickness of the layer is in the 3-10 $\mu \mathrm{m}$ range. It is polycrystalline and contains polygonal (tips labeled "1" and "3") and columnar grains (tip labeled "2"). These tips will be analyzed in the next paragraph.

In order to characterize the crystal structure of this layer, electron diffraction patterns were collected from different tips (Figs. 2b and 2c). The identification of the diffraction spots located along rings, 
with the corresponding diffracting planes through their Miller indices, as well as their interplanar distances are summarized in Table 1. These data allow us to identify the complete set of crystallographic planes as belonging to a face centered cubic (FCC) structure.

Table 1: Identification of the diffraction spots through their Miller indices and interplanar distances, obtained from patterns (Figs. 3b and c) on different tips belonging to the sub-surface layer.

\begin{tabular}{|c|c|c|}
\hline spot \# & hkl & Interplanar distance $(\mathbf{\AA})$ \\
\hline 1 & 111 & $2.54 \pm 0.03$ \\
\hline 2 & 200 & $2.22 \pm 0.02$ \\
\hline 3 & 220 & $1.57 \pm 0.02$ \\
\hline 4 & 311 & $1.34 \pm 0.01$ \\
\hline 5 & 222 & $1.29 \pm 0.01$ \\
\hline 6 & 331 & $1.01 \pm 0.01$ \\
\hline 7 & 420 & $0.99 \pm 0.01$ \\
\hline
\end{tabular}

These data fit very well with those for the $\mathrm{FCC} \mathrm{TiH}_{1.971}$ phase (JCPDS card 07-0370), belonging to the space group $\mathrm{Fm} 3 \mathrm{~m}(225)$ with lattice parameter $\mathrm{a}=4.44 \AA$. This result is in agreement with previous chemical analyses of Aronsson et al. [3], which indicated a high average hydrogen concentration in the layer. Data may also correspond to several $\mathrm{TiH}_{\mathrm{x}}$ phases $(1.9<\mathrm{x}<2)$, slightly tetragonal below room temperature and FCC above (card 25-0983).

Fig. 3a shows the TEM bright-field image of the tip \#1, constituted of 2 polygonal, slightly misoriented hydride grains, which can be seen separately in dark-field images of Figs. $3 \mathrm{~b}$ and c. Here the hydride grains are oriented along the [011] zone axis, which is parallel to the [01|0] zone axis of the $\alpha$-Ti substrate with a hexagonal structure. The latter can be seen in Fig. 3d. Tip \#2 (Fig. 3e) is formed by columnar grains, divided into 3 families (Figs. 3f, g and h). All families are in epitaxial relationship with the substrate and have a $<220>$ crystallographic direction in common. The same kind of crystallographic relationship is observed in tip \#3: polygonal hydride grains at the interface with the $\alpha$-Ti are in epitaxial relationship with the latter showing, simultaneously, a <220> direction in common with hydride grains located far from the interface (for further detail about these crystallographic analyses, see [5]). 
From our observations, we can formulate some hypotheses concerning the shape of hydride grains obtained after phase transformation. First, sand blasting deforms Ti plastically over some microns in depth, introducing crystalline changes such as polygonization and twins. Second, the acid etching transforms the Ti in Ti-hydride with a certain memory of the introduced defects: polygonized zones in Ti result in polygonal zones in $\mathrm{TiH}_{1.971}$ and twins in $\mathrm{Ti}$ may result in columnar grains in $\mathrm{TiH}_{1.971}$. These characteristics coupled with the above epitaxy relationships guarantee, for this layer, the best possible cohesion and adherence to the Ti substrate.

Fig. 4a shows a high density of dislocations in the hydride layer forming a three-dimensional network. Using the classical contrast extinction rules, their Burgers vectors are found to be of the $1 / 2<110>$ type, as in FCC metals and alloys. The dislocation arrangement observed in Fig.4a is typical of a fairly ductile but highly plastically deformed material, which denotes a substantial strain accommodation during the elaboration process. Our observations are in good agreement with previous studies [6] demonstrating the plastic deformation of $\mathrm{TiH}_{\mathrm{x}}(\mathrm{x}=1.58-1.99)$. In Fig. 4b, dislocations have been emitted by the interface in the $\alpha$-Ti substrate. Dislocations in the hydride layer and in the Ti substrate have moved in order to relax the internal stresses generated by the phase transformation. Indeed, the presence of hydrogen atoms increases the distance between neighboring $\mathrm{Ti}$ atoms, which induces compressive stresses in the layer along directions parallel to the surface.

From the observed plasticity of the hydride layer, and from its small grain size and high dislocation density, good mechanical properties (ductility and strength) can be expected a priori.

\subsection{Ti-covered Ti6Al4V alloys}

Fig. 5 shows the SEM cross-sectional image of a Ti6Al4V femoral prosthesis covered with a $\sim 100$ $\mu \mathrm{m}$-wide roughness coating of pure Ti. Besides the surface roughness, we can see many porosities 
and cavities in the thermal-sprayed layer, as expected. Many no contact points were observed between the layer and the substrate along the interface.

The prosthesis shown in Fig. 5 is observed by cross-sectional TEM in Fig. 6. The sample has been thinned down close to the interface, as a result decohesion of the coating took place locally. In the panorama (Fig. 6a), the side numbered "1" is the Ti6Al4V substrate, whereas side $\mathrm{n}^{\circ}$. "2" is the Ti coating. In the substrate side, Ti6Al4V grains are small and highly deformed, as shown in corresponding TEM bright-field image of Fig. 6b. The crystallographic structure expected for Ti6A14V (hexagonal) remains unchanged. Far below the original surface (undeformed region), Ti6A14V grains are large. Further substrate transformation due to the sand blasting can be seen in Fig. 6d: one alumina particle (region numbered "3") remained incrusted, initiating a crack, which probably contributes to the substrate embrittlement. In Fig. 6c, the TEM bright-field image shows the small grains in the coating, which is constituted only of the $\alpha$-Ti hexagonal phase, without any layer between grains. A very small quantity (if any) of oxygen was found dissolved in the coating. The dark-field image shows a high density of dislocations and twins.

A prosthesis covered by a coarse coating is shown in the cross-sectional TEM bright-field image of Fig. 7a. The hole that results from sample thinning has divided the coating in two parts: the substrate/coating interface is seen in the bottom of the image whereas the top of the coating is in the upper part. It is formed by large grains showing only a few defects. An interfacial amorphous film is often observed between two grains of the coating (see detail, Fig. 7b). This absence of contact between grains certainly facilitates debris to be delivered in the body. On the other hand, only a few points of contact are seen between the coating and the substrate (see detail, Fig. 7c) and an interfacial layer is observed at the interface in the coating side. The EDS analyses in Fig. 7d show an increase in the oxygen content from the interface up to $7-8 \mu \mathrm{m}$ inside the coating (region 2 and 3), where it reaches $50 \%$. The electron diffraction patterns indicate the existence of a cubic 
titanium oxide phase in region 3 , which is mixed with the hexagonal Ti6Al4V in region 2 . This oxide is identified as being probably $\mathrm{TiO}_{1.04}$. From these observations, the coating/substrate adherence appears to be very poor, and delaminating can occur at anytime. Far from this region the oxygen content decreases, and only the hexagonal $\alpha$-Ti was found (regions 4-6).

\section{General Discussion and Conclusions}

From our observations we conclude that the same convenient surface roughness was obtained with the two types of process, with many differences, however. These differences concern the surface layer, the interface and the substrate.

We observed crack initiation due to sand blasting in Ti6Al4V substrates. These cracks were not observed in c.p. titanium, neither by SEM nor by TEM. The higher ductility of Ti may prevent this effect, but its mechanical strength is of course lower. As a further point to be studied, it would be also interesting to investigate the possibility of developing and performing an acid etching, similar to the SLA process, on the biphasic Ti6Al4V alloy.

In SLA-treated surfaces, the hydride grains of the surface layer have a crystallographic direction in common, which indicates a high degree of cohesion. Moreover, they are in epitaxial relationship with the substrate, which guarantees the best possible adherence. No delaminating or debris delivered in the body is expected. On the other hand, Ti coatings with coarse roughness show amorphous interfacial films, most probably Ti oxides, between the grains of the coating, as well as a $\mathrm{TiO}_{\mathrm{x}}(\mathrm{x} \sim 1)$ crystalline layer at the coating/substrate interface. The characteristics of this material are, in fact, the opposite of those obtained with the SLA treatment, and delaminating as well as debris delivered in the body can easily occur. As an intermediate situation, the fine-roughness coating, formed by a polycrystalline layer without interfacial films, is expected to have a better 
adherence and cohesion than the coarse-roughness one.

Another important study to be performed in the near future concerns the respective biological role and efficiency in osteointegration of weak and oxidized interfaces, as obtained by thermal spray deposition, and clean and strong ones, as obtained after SLA surface treatment.

\section{Acknowledgements}

Authors thank Institut Straumann AG and Sulzer-Metco for providing samples, IMX-EPFL for indentation facilities and CIME-EPFL and CEMES/CNRS-Toulouse for electron microscopy facilities. D.C. thanks EPFL for granting him a leave of absence to pursue part of this research in Lausanne. The financial support from Fonds National Suisse pour la Recherche Scientifique (grant nr. 2134-062611.00/1) is gratefully acknowledged.

\section{References}

[1] M. Wieland, Experimental determination and quantitative evaluation of the surface composition and topography of medical implant surfaces and their influence on osteoblastic cell-surface interactions, Ph.D. thesis no. 13247, 1999, ETH Zürich, Switzerland.

[2] C. Massaro, P. Rotolo, F. De Riccardis, E. Milella, A. Napoli, M. Wieland, M. Textor, N.D. Spencer, D.M. Brunette, Comparative investigation of the surface properties of commercial titanium dental implants. Part I: chemical composition, J. Mater. Sci.: Mater. Med. 13, (2002) 535 548.

[3] B.-O. Aronsson, B. Hjörvarssojn, L. Frauchiger, M. Taborelli, P.-H. Vallotton, P. Descouts, Hydrogen desorption from sand-blasted and acid-etched titanium surfaces after glow-discharge treatment, J. Biomed. Mater. Res. 54, (2001), 20 - 29. 
[4] See Web site: www.sulzermetco.com/desktopdefault.aspx/tabid-1740/3392 read-5304/

[5] E. Conforto, D. Caillard, B.-O. Aronsson, P. Descouts, Crystallographic Properties and Mechanical Behaviour of Titanium Hydride Layers Grown on Titanium Implants, Phil. Mag. 84, (2004), $631-645$.

[6] P.E. Irving, C.J. Beevers, Some observations on the deformation characteristics of titanium hydride, J. Mater. Sci. 7, (1972) 23 - 30.

\section{Figure Captions}

Figure 1: a) SEM image of an alumina particle, from sand blasting, incrusted in the SLA-treated Ti surface and b) high-load indentation print, both showing a few cracks around them. d) SEM image of the surface layer strained by $2 \%$ in tension after bending (see lateral view in c). Only a few cracks (arrowed) can be seen along the direction perpendicular to the straining direction (noted SD).

Figure 2: a) TEM cross-sectional bright field image of the $\mathrm{Ti}$ surface treated by SLA at low magnification. b) and c): Electron diffraction patterns obtained from two neighboring tips, evidencing an FCC structure. The spot numbers refer to Table 1.

Figure 3: a) TEM cross-sectional bright field image of tip 1 at its interface with the Ti substrate; b) and c): Corresponding dark field images obtained by diffraction of (200) planes showing two slightly misoriented $\mathrm{TiH}_{1.971}$ grains. d) Corresponding dark field image of the $\mathrm{Ti}$ substrate in the same tilt conditions using the diffraction of the (0002) planes. e) Bright field image of tip 2 showing columnar grains and their interface with the $\alpha$-Ti; $f-h$ ) Corresponding dark-field images of the 3 
families of columnar-shaped grains. i) Bright field image of tip 3 containing polygonal grains. j) Dark field image of the hydride grains at the interface with $\alpha$-Ti, in the [112] zone axis and using the diffraction of $\{1 \mid 1\}$ planes (intense spots); k) Same area, close to the extremity of the tip, in the [114] zone axis, using the diffraction of the FCC $\{220\}$ planes.

Figure 4: Dislocations in the hydride layer and in the Ti substrate close to the interface. Dislocations "d" have been emitted by the interface in A.

Figure 5: SEM cross-sectional image of a Ti6A14V femoral prosthesis covered with a thermalsprayed, coarse roughness titanium layer, showing porosities and cavities.

Figure 6: TEM cross-sectional images of Ti6Al4V prosthesis covered with fine-roughness titanium. a) Panorama view of the specimen; b) bright field images of the Ti6Al4V substrate: at left, the deformed region (surface) and, at right, the undeformed one (far from the surface); c) TEM bright and dark-field images of the titanium coating; d) Incrusted alumina particle in the substrate and crack initiation.

Figure 7: TEM cross-sectional analysis of Ti6Al4V prosthesis covered with coarse-roughness titanium. a) Low-magnification bright-field image showing the substrate/coating interface and part of the coating; b) detail of the coating, showing an amorphous interfacial film between Ti grains; c) Substrate/coating interface with only a few points of contact and an interfacial oxide layer; d) EDS analyses between points "1" (substrate) and "6" (in the coating, far from the interface), showing the evolution of the oxygen content, as a function of the distance to the Ti6Al4V substrate. 


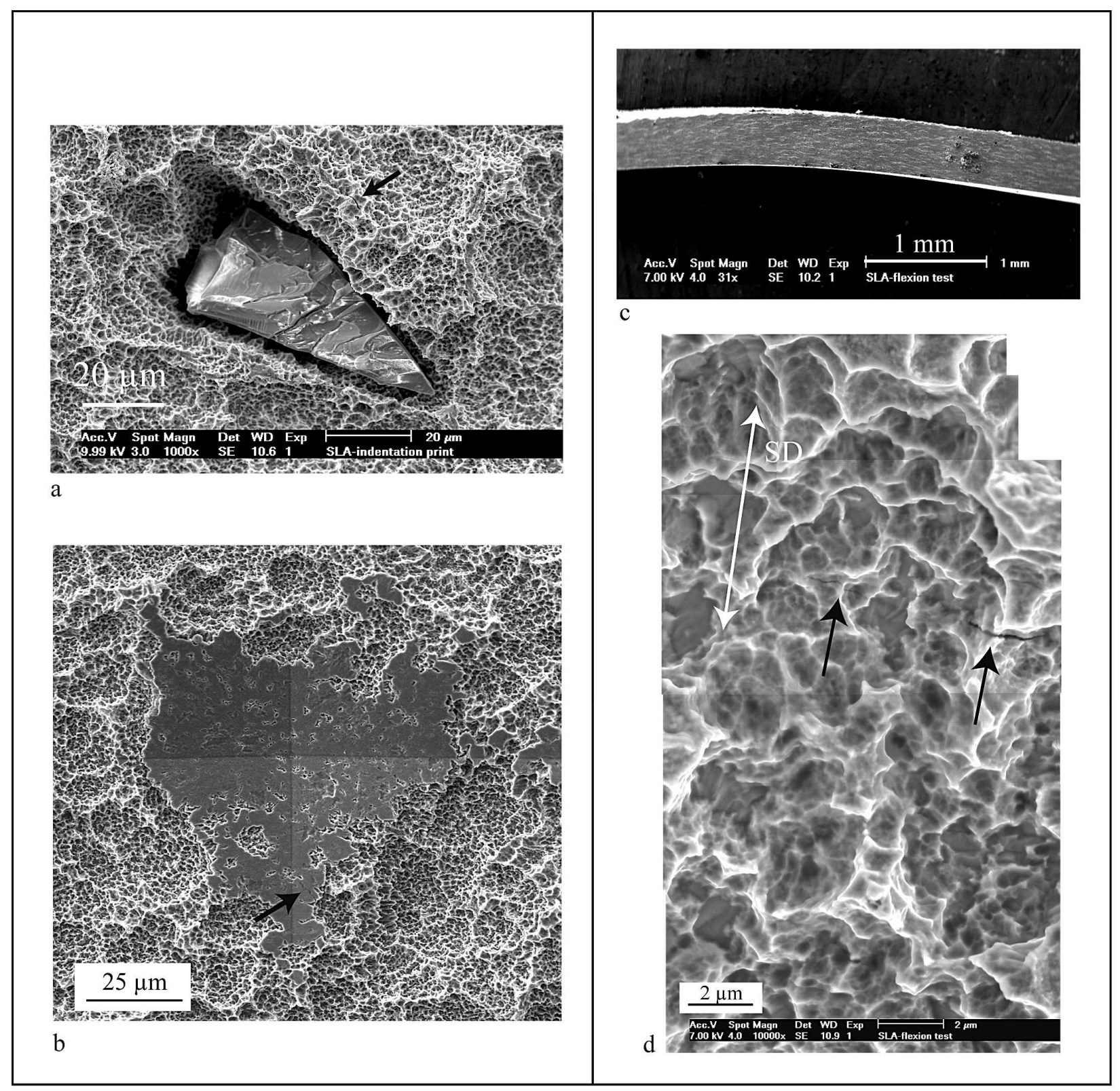

Fig. 1 


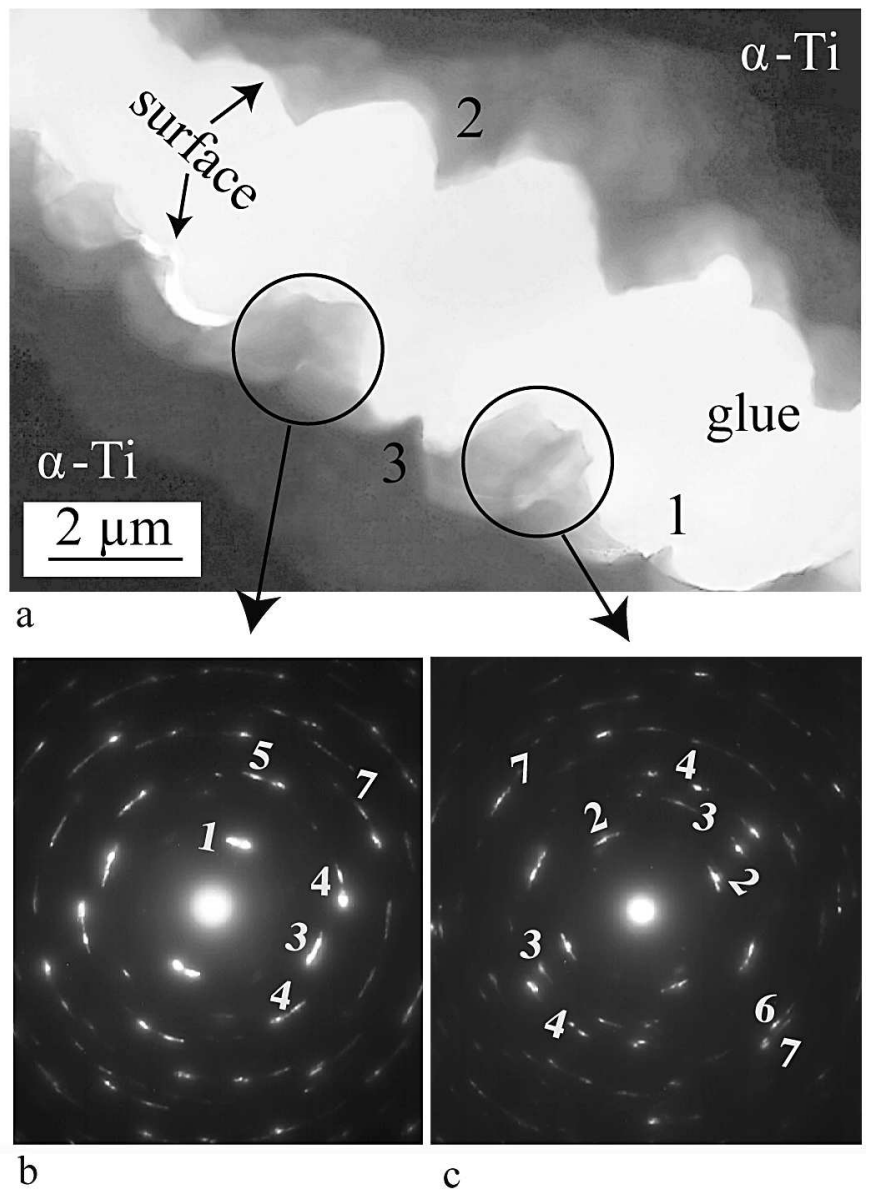

Fig. 2 
Tip \# 1 :

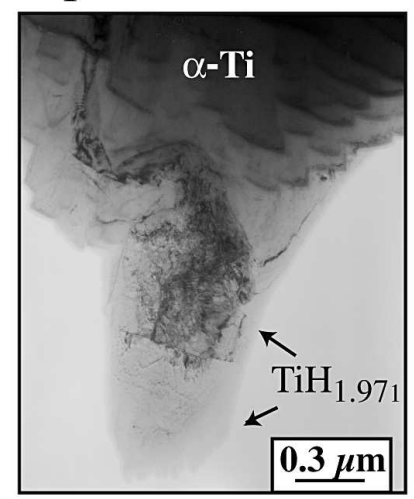

a

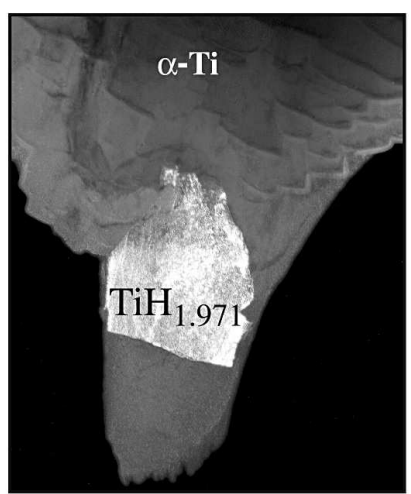

b

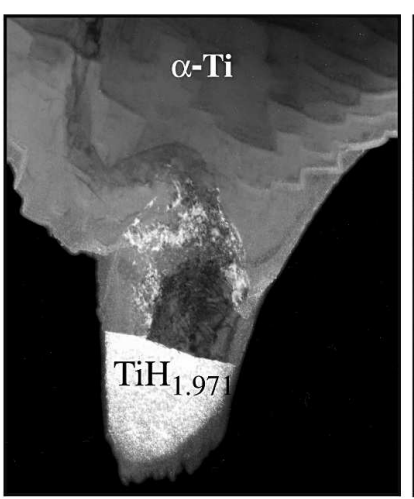

c

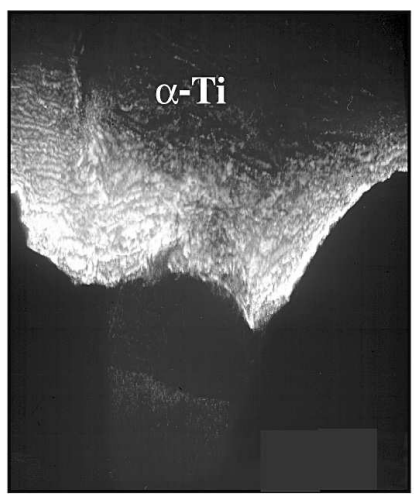

d

Tip \# 2 :

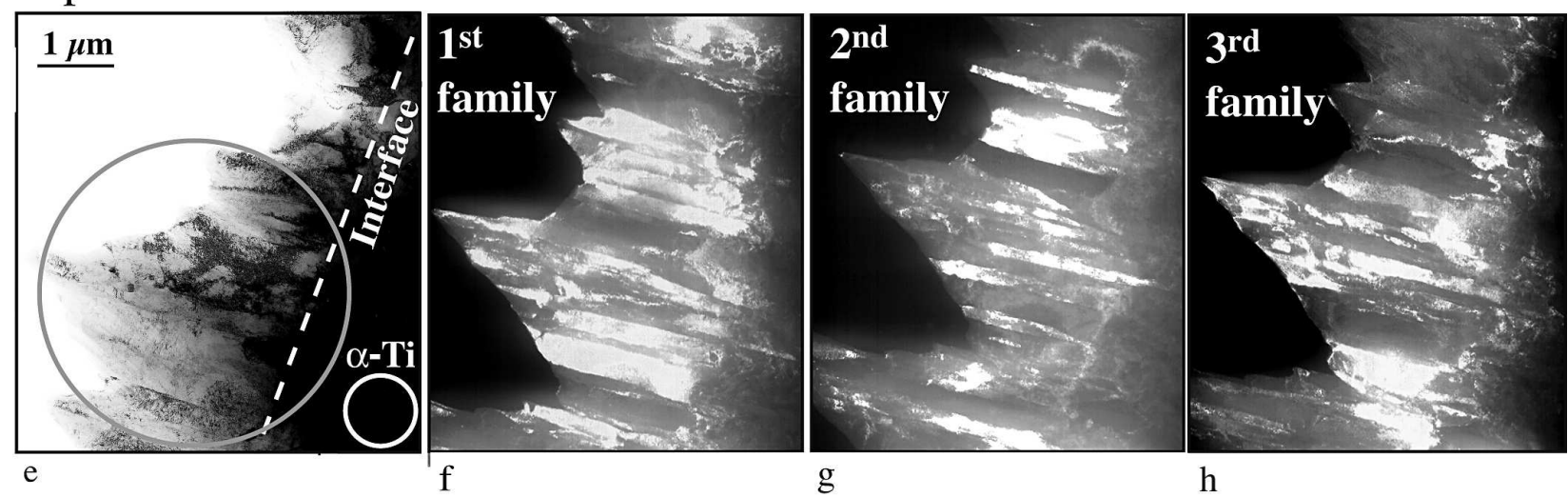

Tip \# 3 :

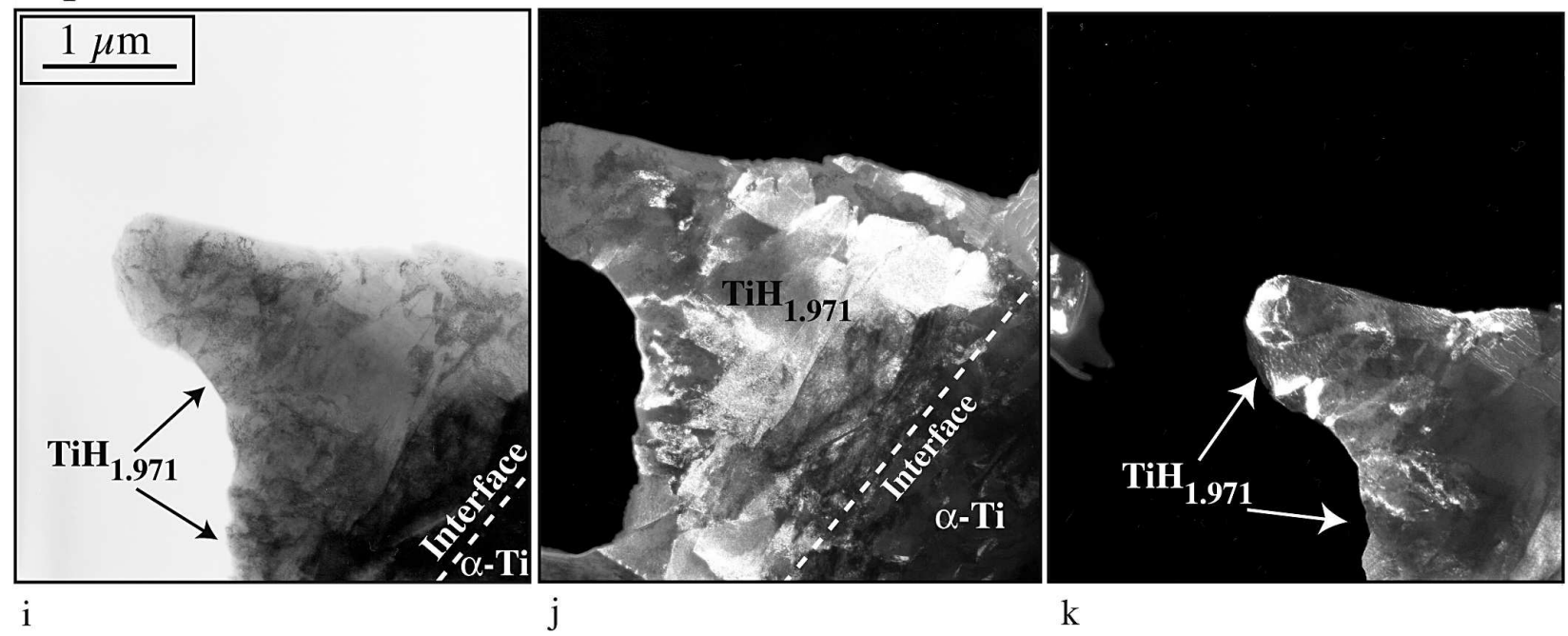

Fig. 3 


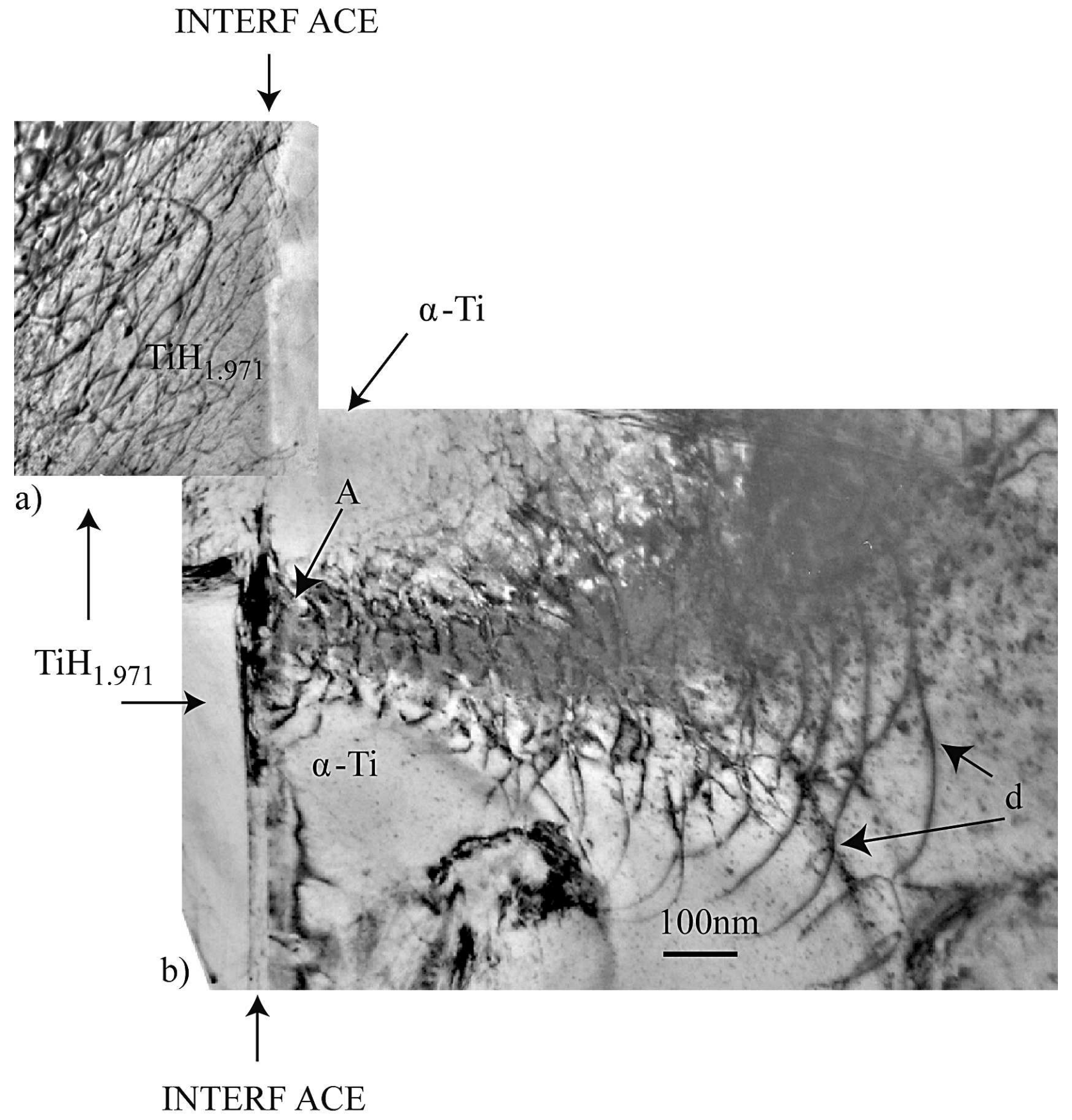

Fig. 4 


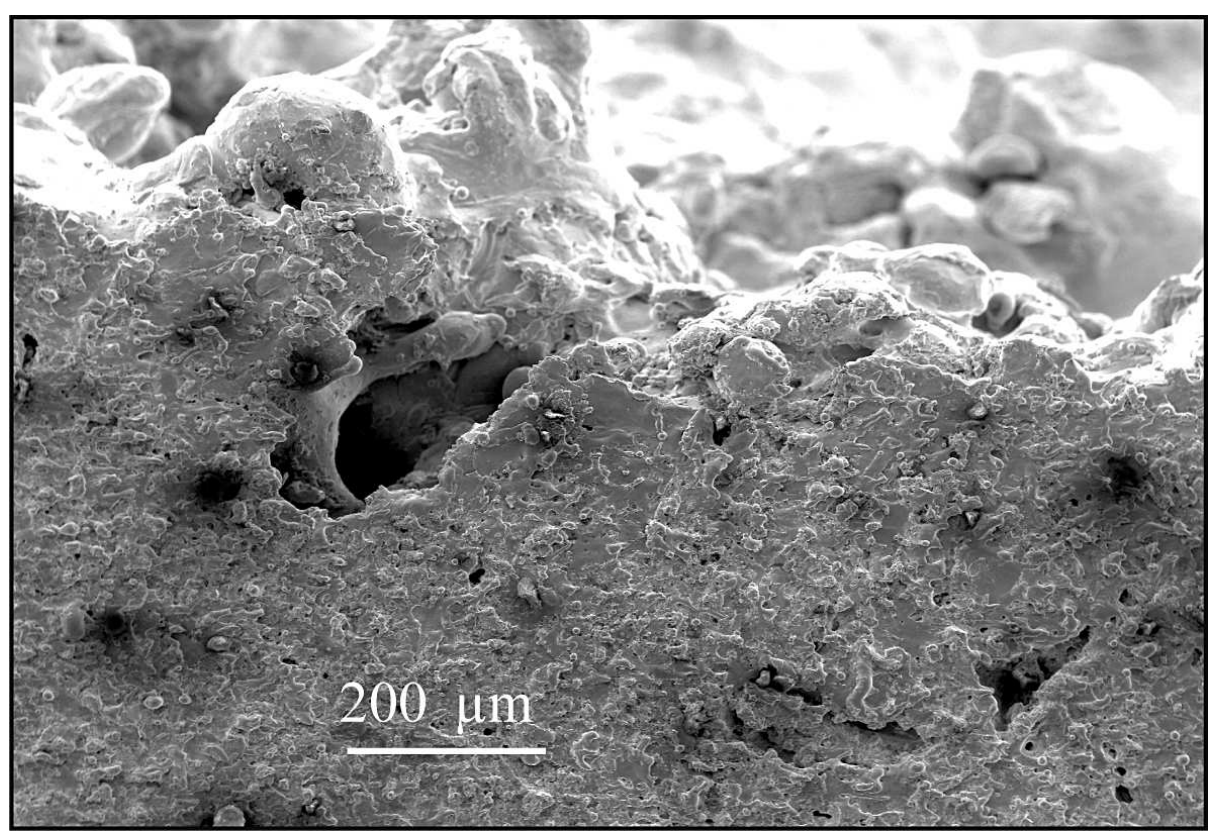

Fig. 5 


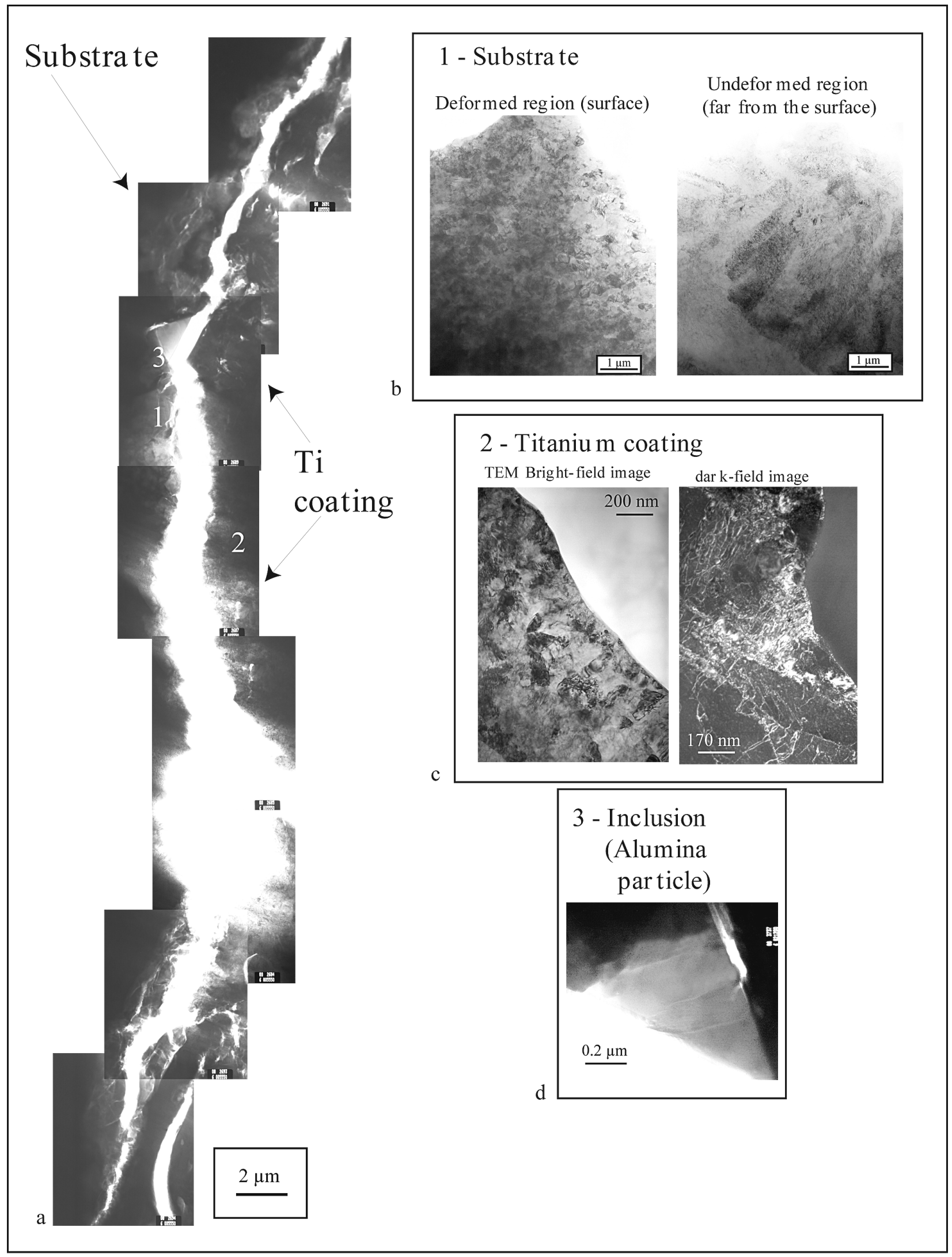

Fig. 6 

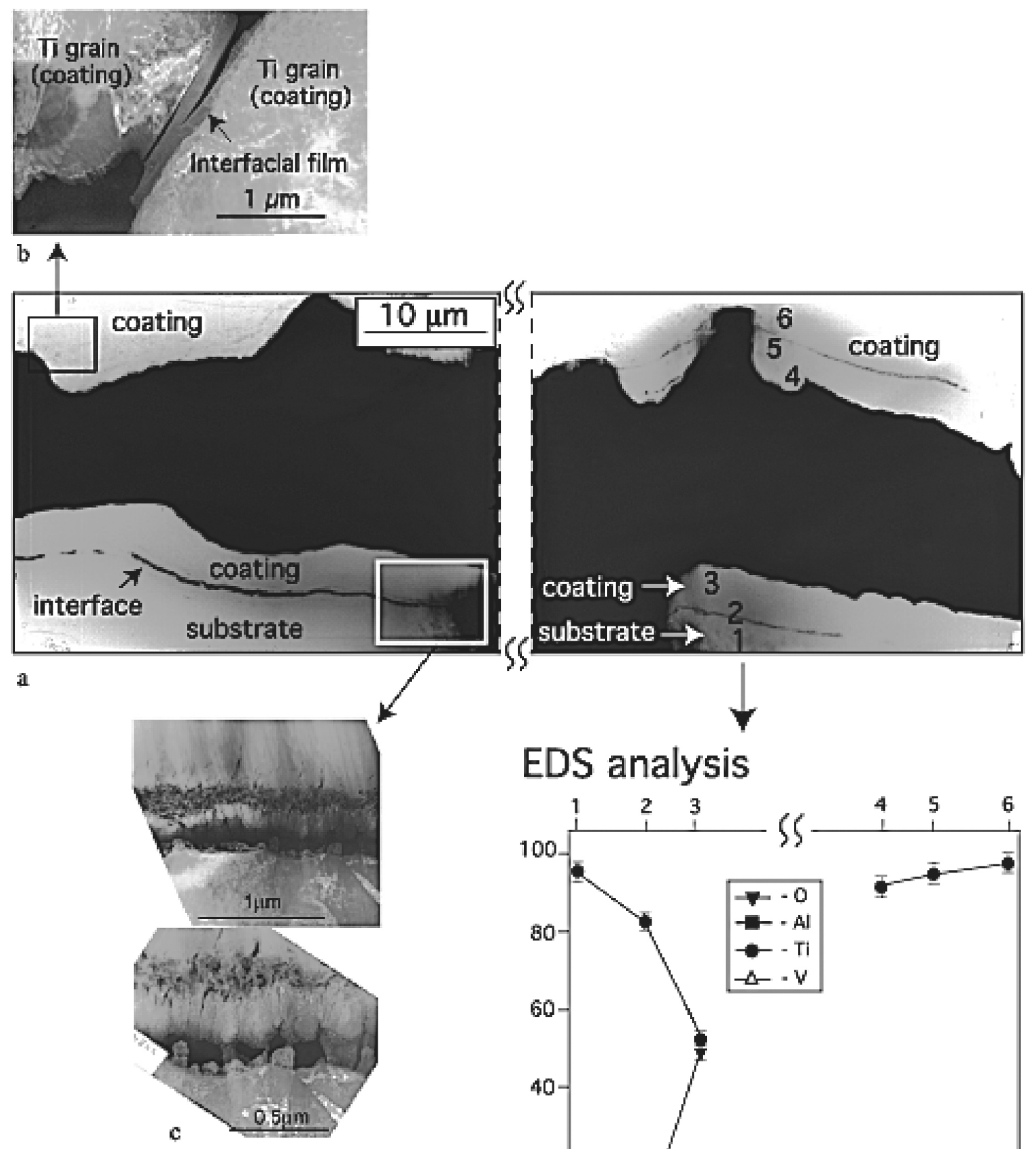

\section{EDS analysis}

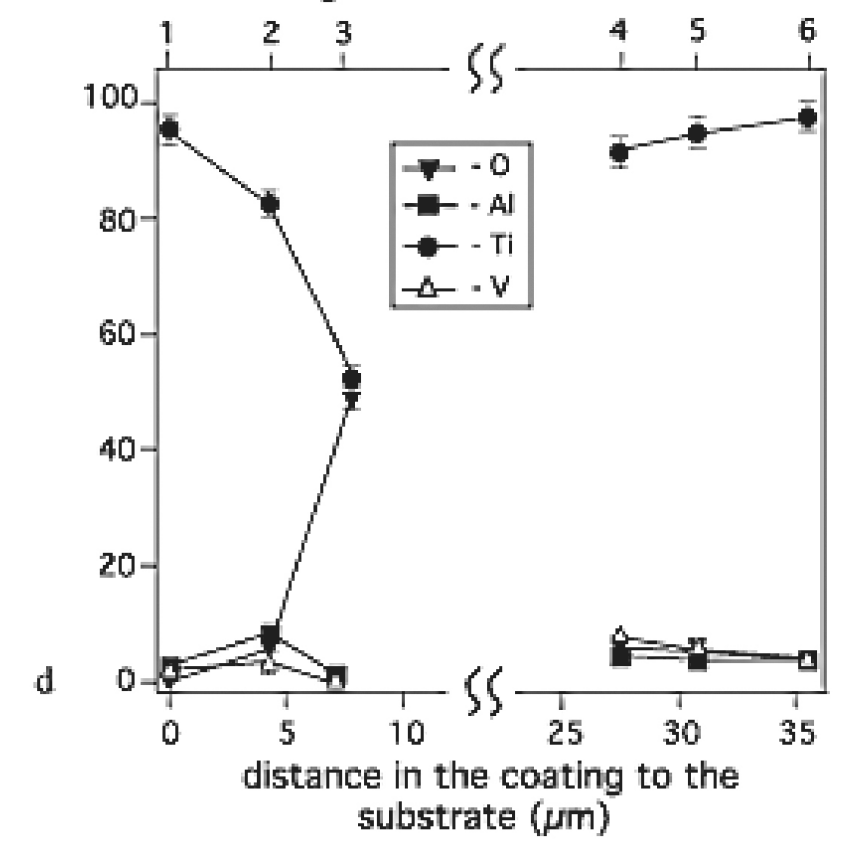

Fig. 7 